\title{
The Fruits of Intellectual Production: Economic and scientific specialisation among OECD countries
}

\author{
Keld Laursen \\ Corresponding author, Centre for Economic and Business Research (CEBR), Danish Ministry \\ for Trade and Industry, Langelinie Allé 17, 2100 Copenhagen Ø, Denmark, and \\ Department of Industrial Economics and Strategy, Copenhagen Business School, \\ Howitzvej 60, 2000 Frederiksberg, Denmark, E-mail: kl.ivs@cbs.dk \\ and \\ Ammon Salter \\ Complex Products and Systems Innovation Centre (CoPS) and the Programme in Innovation \\ in the Built Environment, SPRU: Science and Technology Policy Research, University of \\ Sussex, Mantell Building, Brighton BN1 9RF, UK \\ E-mail: A.J.Salter@ sussex.ac.uk
}

First draft: this version August 22 $2^{\text {nd }}$

Abstract: This paper explores the relationship between economic and scientific specialisation. Debates over the role of science-based innovation focus on the link between strength in fields of science and national competitiveness. Yet there are few empirical studies that link the science base to the economic sphere. Since Marx, there has been a fundamental debate about the link between science and the economic system. In this context, Polanyi argued that the developments in the science system take place largely independent of economic factors, whereas Bernal saw the science system as the product of the economic superstructure.

Based on publications by private business firms, we conjecture the relevance of 77 scientific fields for 17 manufacturing sectors. This procedure hinges on the assumption that if firms in particular sectors publish papers in particular fields of science, then they - at least partly - do it because they have, and wish to maintain, an "absorptive capacity" in the relevant scientific fields. Using this concordance scheme, we analyse the relationship between the strength of 17 OECD countries in 77 scientific fields and economic specialisation of those countries, across 17 manufacturing sectors. One key hypothesis in this context that scientific specialisation should be expected to be correlated with economic specialisation for what concerns non-science-based sectors, while economic specialisation in science-based sectors are expected to be associated with scientific strength in the relevant fields of science. The econometric methodology consists of panel data models and in the estimations of the determinants of economic specialisation, we control for price (unit labour costs) and for nonprice-factors (technological specialisation). Production specialisation is taken as the indicator of economic specialisation. Overall, we find evidence to support our hypotheses.

Keywords: Scientific specialisation, international economic specialisation, bibliometric data JEL: $\quad$ O31, C23

Paper prepared for the ECIS Conference on The Future of Innovation Studies to be held in Eindhoven, 20-23 September 2001. 


\section{Introduction}

This paper explores the relationship between scientific activities and economic specialisation. Today, debates over the role of science-based innovation focus on the link between strength in fields of science and national competitiveness. For example, many authors argue that a strong science-base can help to improve national competitiveness. Yet there are few empirical studies that link the science base to the economic sphere. Since Marx, there has been a fundamental debate about the link between science and the economic system. Polanyi (1962) argued that the developments in the science system take place largely independent of economic factors, whereas Bernal (1939) saw the science system as the largely product of the economic superstructure. By establishing regularities and discussing the causality between economic specialisation and the strength of the pool of national scientific knowledge, across a number of advanced countries, the paper provides new evidence on the relationship between science and the sphere of production.

The research is based on link between specialisation in scientific publications and economic activities at the national and sectoral level. In order to explore this link, we develop a concordance between 77 ISI scientific fields and 17 manufacturing sectors using a database of industrial publications in the UK from 1981 to 1994. Scientific publications are seen to represent the knowledge base of the industrial sector, the location of the ideas and techniques that underpin economic development. The production statistics represent the sphere of economic activities. With our concordance between patterns of production and science, we explore the relationship between patterns of specialisation across 17 advanced OECD countries. The data used for the study is drawn from the ISI, SPRU BESST, the US Patent Office, and from the OECD STAN databases.

The analysis shows that most industries draw from a wide number of scientific fields. We find that for many science-based and scale-intensive sectors, there is a statistically significant relationship between scientific activity and economic specialisation. This suggests that science and the sphere of production are, indeed, related. In this respect, Marx was right. The analysis also shows that inter-industry differences matter greatly in determining the link between scientific and economic specialisation.

The organisation of the paper is as follows. Section 2 explores the relationship between science and the economic system, drawing from the work of Marx, 
Rosenberg, Bernal and Polanyi. Section 3 describes the method of the study and presents descriptive statistics about the scientific and economic specialisation across the sample population. Section 4 contains the econometric analysis and Section 5 concludes.

\section{Theoretical Considerations}

The relationship between science and the economy has come to fore the policy discussion over the emergence of the knowledge-driven economy. A central point of contention is that way new ideas are generated, diffused and used in the economic system can have important implications for national competitiveness. New economically useful ideas are often generated through investments in the science system and many OECD countries have made new efforts to try to link their science system to the economic needs of industry. This interest in the relationship between science and production is not new, however. As Rosenberg argued, Karl Marx was one of the first to explore the link between science and the economic system. In his and Engels' Communist Manifesto, Marx argued that the material conditions of production create intellectual production (Marx refers to science as intellectual production). Engels stated "from the beginning, the origin and development of the science has been determined by production." The changes in the sphere of production shape knowledge production by determining what is necessary, useful or valuable.

"Science does not grow or develop in response to forces internal to the science or the scientific community. It is not an autonomous sphere of human activity. Rather, science needs to be understood as a social activity which is responsive to economic forces. It is man's (or women's) changing needs as they become articulated in the sphere of production which determines the direction of scientific progress" (Rosenberg, 1976: 128).

Despite this extreme position, Rosenberg argues the demand argument of Marx (and Engels) is often overemphasised in the literature on technical change (Rosenberg, 1976). Marx recognised that science had only become tightly linked to production when science itself reached a particular state of development. It was through the rise of specialisation (i.e. the increasing division of labour) and the application of science to the production process that the link between science and the sphere of production was created. When production was re-organised on the basis of the needs of capital, capital was able to use the instruments of science and technology 
to, in turn, reshape its production process. This process of mutual support and development created a dialectical relation between science and the sphere of production. Marx saw that the ability to "apply science to the productive sphere turns upon industry's changing capacity to utilise such knowledge" (Rosenberg, 1976: 129, emphasis in original ). It is the capability of the productive sphere to use knowledge that creates and ensures the dialectical relation between the two spheres of activity.

How is, then, is science shaped by the sphere of production? Rosenberg lists several possible mechanisms:

- direct financial support;

- the expectations of returns motivates individuals to solve a particular scientific problems;

- the needs of industry act as a powerful agent in calling attention to specific problems;

- normal production activities throw up physical evidence of great importance to scientific development (Rosenberg, 1976);

- hegemonic control, i.e. shaping of social norms, views and goals.

An updated and expanded version of Marx's view of science was reflected in the work of J. D. Bernal (1939). Bernal argued that governments could use science for achieving social and economic goals. Like Marx, Bernal saw the potential to use intellectual production means for expanding and creating material choices, e.g. governments could choose which areas to fund and thus achieve social and economic objectives. Science could be harnessed to help achieve social and economic goals, linked to the needs of the sphere of production.

In contrast to Marx and Bernal, Polanyi (1962) argued that the science system operated largely independently of the government and societal control. He defended the "Republic of Science". Intellectual production should be divorced from the sphere of production. New ideas are developed through the insight, experience and experimentation of individuals and teams working within the institutions of science, Polanyi argued. These processes of discovery, review and experimentation cannot be controlled or shaped by purely social or economic objectives. For example, Einstein's work on relativity was not motivated or funded in the pursuit of a social or economic objective. It took place outside the control of the state. It sought fundamental understanding outside of material conditions. Polanyi argued that Bernal's approach for making science closely follow social and economic objectives would have a pernicious impact of scientific development, limiting the develop of new ideas. 
Moreover, Polanyi argued that many social and economic objectives are well beyond the capabilities of scientific research.

This tension between the Polanyi's Republic of Science and Bernal's instrumentalist views of science has been reflected in science and technology policy choices of governments. Many advanced OECD countries have attempted to strike a balance between the desire to use science for social and economic objectives, on one hand, and the belief that science should be left partly independent from social needs and economic objectives, on the other hand. Vannevar Bush's The Endless Frontier expressed this widespread post-war compromise (1945). In the Bush compromise, the research-funding model supported by government was neither a pure republic of science model nor a science system determined by social and economic needs. Research funding was provided through a mixture of programmes, some these programmes focused on fundamental research (the republic of science model), and targeted programmes, focused on more immediate social and economic objectives. The general balance between these two modes of funding has shifted over time, but overall the research systems in the OECD have been responsive to societal needs. This is, in part, reflected in the majority of public funding for research being concentrated in practically oriented disciplines, such as engineering, medicine and agricultural science (Pavitt, 2000).

However, since the early 1980s, the Bush compromise has come under increasing strain. Many argue that new forms of knowledge production reshape the link between science and the economic system and make the Bush compromise untenable (Gibbons et al., 1994). They point the rise of the knowledge-driven economy, arguing in the economic system is becoming more and more dependent on science. The traditional role of actors in the knowledge production system is blurring and knowledge production is becoming pluralistic with a variety of public and private actors creating and competing in new knowledge-based industries.

As part of this questioning of the Bush compromise, there has been an increasing emphasis on the use of the science system to support economic development. This new approach sees universities act as engines of economic growth, providing ideas to fuel economic development (Etzkowitz et al., 2000). As part of this move away from the Bush compromise, governments often wish to maintain greater control and management of research. Science is too important to be left to the scientific community is a common argument. Government action is required to ensure the 
science system delivers on its economic potential. New policy instruments, such as Technology Foresight, are seen to provide opportunities to find a better integration between academic and industrial research objectives (Martin and Johnston, 1999).

This shifting policy environment reflects on-going debates in innovation studies over the role of demand and supply in shaping innovation. Early work on patents by Schmookler (1966) suggested that innovation was largely shaped by market demand. Boosting demand would also boost innovation and therefore improve scientific progress. Rosenberg and Mowery challenged this conclusion, arguing that many areas of science of immune to demand and the impact of science on technology and therefore on the economic structure has been profound. They argued that there is an interactive coupling between market demand and scientific and technological possibilities in the process of innovation (Mowery and Rosenberg, 1979; Freeman and Soete, 1997: 200).

In order to overcome this debate, Nelson argued that it is important to realise that science and the sphere of production co-evolve, that is science and economic system mutually reinforce each other over time (Nelson, 1994). For example, strength in a particular industrial sector might lead a government to investment in a research programme associated with that sector. Nelson describes the general process of institutional development and adaptation as innovation systems respond to opportunities opening up both in science and industrial practice. In this model of coevolution, it is, however, difficult to disentangle the change roles of science and economic activity in over time. For those who see science becoming increasingly important for innovation, the co-evolution argument is not nearly sufficient. They wish to go well beyond this historical perspective as they see opportunities for proactive strategies to harness the economic potential of science.

A key part of the argument that science is the increasing important for innovation is the rise in the number of citations in industrial patents to academic research. Narin et al. (1997) found a three-fold increase in the number of citations to academic research in US patents over the 1990s. This shift toward higher number of citations of academic research in industrial patents suggests to many the increasing sciencedependence of technology and vice-versa. Hicks et al. (2001) shows that the highest growth in citations to academic research in industrial patents has been located in health-related sectors. In information technology-related sectors, there is limited evidence of an increasing science-dependence. Hicks et al. conclude that in 
information technology industries the pace of technical change is too fast for the pace of scientific research and publication.

For Narin et al. and others the increasing prevalent links between science and technology suggest that in the knowledge-driven economy that scientific research plays an increasingly important role in shaping patterns of growth. Investments in science can play a leading role in support industrial innovation, especially in health related sectors, and they can help nations to secure a dynamic, successful economy.

The increasing importance of science in industrial practice is often linked to changes in the nature of research and development strategies among large firms. More and more organisations are subcontracting, collaborating and internationalising their R\&D budgets. These new $R \& D$ strategies seek to use universities as listening posts for new ideas and technological possibilities (Christensen, 1997). At the same time as industrial firms are reaching out to universities for new ideas, universities are seeking support from industry. The rise of university patenting and other forms of intellectual property indicate this general trend (Hicks et al., 2001; Mowery et al., 2001).

Many universities have created incubators, venture capital funds and science parks with the direct purpose of increasing their impact on the sphere of production. Etzkowitz et al. sees the rise of the entrepreneurial university, increasingly raising funding from private sources and freeing itself from public control. Pavitt also argues that fundamental changes in nature of technological development via new information technologies have created possibilities for new science-based firms to emerge from universities. Technical changes in the tools of engineering design (rapid prototyping, simulation and optimisation tools) create opportunities for science-based university firms to explore technical concepts and products, to act as product developers and to offer specialised technical services to industrial practice (Pavitt, 2000).

Despite this enthusiasm for linking science with opportunities in the sphere of production, the empirical evidence on the economic benefits of publicly funded research is mixed (Salter and Martin, 2001). It has been difficult for economists and others to find a direct link between support for research and industrial innovation. Part of the problem is related to the problem of measurement. Often the links between research and economic activities are subtle, varied and indirect. It remains difficult, if not impossible, to assess the economic impact of a piece of research in the short term. Mowery and Rosenberg argued that knowledge from science is transferable to production, but often it is limited in its range of application (Mowery and Rosenberg, 
1979: 237). Pavitt argues "the route from discovery to application is often long and tortuous, involving the movement of knowledge, techniques and instruments from one discipline to another" (Pavitt, 2000: 11).

There are, moreover, considerable differences across industries in the importance of science for innovation. In pharmaceuticals and biotechnology, the link between science and economic activities appears to be quite strong. The findings of research in the life sciences can often have direct economic implications. This demonstrated by a high number of university spin-offs in these sectors and the high number of academic citations in industrial patents (Hicks et al., 2001). Yet, in other industries, such as auto manufacturing and aerospace, the links are much more varied. In their study of technological opportunities, Klevorick et al. (1995) found considerable inter-industry differences in the importance of university research as sources of innovation. Leading users of industrial research were the largely science-based sectors, such as pharmaceuticals and chemicals. In non-science based sectors, the link between research and innovation was usually mediated by the transfer of skilled graduates from universities into practice and through the transfer of new scientific ideas into engineering school educational programmes (Nelson and Rosenberg, 1994). Given the fact that a strong link between innovation and economic performance has been confirmed for a large share of industrial sectors (e.g. Soete, 1981; Amable and Verspagen, 1995), the above mentioned studies point in the direction of a particularly strong relationship between relevant national scientific performance and national economic specialisation, in sectors which can be termed science-based sectors.

In order to better understand the contribution of different fields of science to innovation, Klevorick et al. broke down the contribution of science into different disciplines. Their study lists 14 different scientific disciplines and, for each industry, respondents were asked to indicate the importance of these different disciplines for their innovation processes. The results confirmed the finding that industrial practice often relies on several different disciplines. For example, auto-manufacturers used traditional engineering disciplines, such as mechanical engineering and more basic sciences, such as physics and mathematics. This empirical finding was supported by the Pace study. It also explored the use of different disciplines (10 disciplines) across different sectors in Europe. It found that industries differed in the extent to which they drew from science and across different scientific disciplines (Arundel, van de Paal and Soete, 1995). 
Most studies in this area have, however, relied on indicators of science, such as papers and technology, such as patents. Few studies have linked indicators of science and technology to the sphere of production. Both the Yale and Pace study show that industries draw from a variety of scientific fields and, in this sense, all industries rely on a broad range of knowledge to underpin their activities. Yet the analysis contained Klevorick et al. and Arundel et al. does not provide a detailed picture of the links between individual sectors and particular disciplines of the science. Both studies used a limited range of disciplines. They also rely on the ability of individual firm respondents to assess the importance of these disciplines to their firms' innovation processes. In some cases, the number of respondents per industry was modest. For example, in the Klevorick et al. in almost half of the industries sampled the number of respondents was two or less (Klevorick et al., 1995). In our approach, we attempt complement these survey-based approaches by using aggregated industrial statistics and more detailed data on scientific publications.

The use of industrial scientific publications data for describing the character of the knowledge underpinning innovation in particular sectors has become relatively common. Narin and Olivastro (1992) and Godin (1996) used publication data to map the knowledge base of individual sectors. Hicks argued that firms use scientific publications to signal their competencies to others, to gain access to scientific networks and to recruit skilled graduates (Hicks, 1995). By exploring these publications, it is possible to develop an understanding of individual sector's knowledge-base and to explore the changing role of science in the innovation process. However, few of the studies of using industrial publications have broken down these publications to a low level of disaggregation. For these researchers, broad patterns of publication provided sufficient information for describing the general knowledge base of individual sectors.

More detailed work on linking patterns of publication to industrial sector has been recently completed by Arundel and Geuna (2000). Using a mixture of survey and publication data, they demonstrate the key role of the domestic science base in influencing patterns of innovation across a wide variety of sectors. The data also shows that the pharmaceuticals sector has the most internationalised knowledge-base of different industrial sectors (Arundel and Geuna, 2000). Arundel and Geuna use a matrix of industrial sectors by fields of science based on expert opinion. Our approach is similar, but it is based on actual industrial publications by sector. 
In a corresponding study, Brusoni and Geuna (2001) use country-level indictors of publications (EU 15, Japan, and US) to explore integration and specialisation across fields and types of scientific research in chemistry, medical and pharmacology. Brusoni and Geuna assess degree of persistence in the specialisation profile of countries over time. This variable is combined with a new variable that assesses the degree of integration in countries across different types of research (basic, applied, development and engineering). They find that specialisation profiles of countries are relatively persistent over time and that the countries with the highest level of integration, that is, countries who publish across all four types of research seem to have the highest performance, such as the US and Germany.

To sum up our discussion on the relationship between the economic and the scientific spheres across nations, we (i) expect that relevant (to each industry) scientific activity co-evolves with economic (production) specialisation. Moreover, we (ii) expect firms in industrial sectors to draw on a variety of scientific disciplines, and (iii) that there is a strong link between relevant scientific performance (measuring the ability to produce science at a world class level) and production specialisation in science-based industries. Since the relationship between the two spheres is much more indirect, when dealing with non-science-based industries, we (iv) expect that there is a positive correlation between relevant scientific specialisation (not necessarily reflecting world-class science, but only indicating a relatively strong position within the given country) and production specialisation in some of the non-science-based industries.

\section{The data}

The bibliometric data used for the analysis is drawn from the ISI database and from the SPRU BESST database on UK publications (for more information on BESST database see Hicks and Katz, 1997). Based on the SPRU BESST database's data on the publishing activity by UK firms over the period 1981-1994, we conjecture the relevance of 77 scientific fields for 17 manufacturing sectors. This procedure hinges on the assumption that if firms in particular sectors publish papers in particular fields of science, then they — at least partly — do it because they have, and wish to maintain, an "absorptive capacity" in the relevant scientific fields. The ISI data base contains publication data for 105 fields of science for 176 countries over the period 1981-1998. Since we want to use the BESST database for linking up the STAN and 
the ISI databases, and since the BESST database does not follow the original ISI nomenclature, we end up with 77 fields of science (for more details, see Sub-section 3.1 below). The economic data is taken from the OECD STAN database (1998 edition), while patent data is obtained from the US Patent Office. Since our patent data ends in 1993, we use data from all sources over the period 1981-1993. Moreover, we use the information for 17 countries - the maximum number of countries in the STAN database with relatively complete data for all of our variables.

This section will first spell out how we have constructed the concordance, linking fields of science to production statistics. Moreover, since the concordance table can in itself be revealing when exploring this link, we also devote some space to the analysis of some of the properties of the concordance table (in Sub-section 3.1). We then (in Sub-section 3.2) explain how the table is used for constructing the variables representing scientific strength and specialisation to be used in the subsequent econometric analysis (in Section 4). All other variables to be used in the econometric analysis are presented as well.

\subsection{The concordance table linking science and production}

As argued above, by exploring patterns of publications by firms in an individual sector, it is possible to understand how firms draw and exploit different pools of scientific knowledge. Publications in a particular scientific field can be seen to represent an industry's "watching brief", a mechanism for firms to keep track of events and ideas in these scientific disciplines. In this respect, industrial publications reflect the absorptive capacity of a sector, the extent to which a sector draws from different fields of science to underpin its innovation processes.

In order to construct our concordance, we separated out the scientific publications of industrial firms in the UK research system. For this analysis, we used 292 firms, each of whom had at least 10 scientific publications. We then divided these firms into 17 industrial sectors (following the STAN classification), drawing from an existing classification developed by Hicks and Katz (1997) and based on the Financial Times list of companies. For each firm, we explored their main line of business, using annual reports and business publications, and placed that firm in the industrial sector that best corresponded to its profile of production. We were able to classify 172 firms according to this method. Those firms where information about their main line of business was unavailable were removed from the analysis. 
Table 1 lists the number of publications by industrial sector and the numbers of firms included in the analysis. Due to differences between the ISI list of disciplines and the list of disciplines used in the BESST database, it was necessary to integrate the two different lists of disciplines in a master list. The aggregation was completed by collapsing some groups into each other based on the authors' estimates of where these disciplines overlapped. For example, the BESST database had six disciplines under computer science and the ISI had one. In this case we collapsed the six BESST disciplines into the ISI framework. By following this procedure, we ended up with 77 fields of science, organised according to the ISI nomenclature

The database is based on data from the UK alone. It would be useful in the future to use a wide spread of industrial publications drawn from a variety of countries. Not only would ensure a greater reliability of data, it would also be possible to vary the time period for the analysis. Data on the citations was removed from the analysis. Citation data is highly skewed and it would require a different approach to the one used here to integrate it into the analysis. However, future research in this area might find citation data to be a useful complement to the total number of publications.

Table 1 demonstrates that each sector is highly multidisciplinary; that is, it is active in wide number of different scientific fields. The industrial chemicals appears to be the most active industrial sector with the broadest number of publications across the scientific fields (75). Industrial chemicals is followed by pharmaceuticals (73) and stone, clay and glass (65). Motor vehicles appears to be the least diverse industrial sector, but even here it is possible to find publications across 19 scientific fields. The Herfindahl Index provides a measure of the concentration of scientific papers across the different scientific fields for each industry. The index only focuses on fields in which there was at least one published paper by that industry. Petroleum refining and industrial chemicals again appear to be the most diverse industry using this measure, whereas electrical machinery and communication equipment were the most concentrated. Using a simple correlation between number of papers and degree of concentration, we found no relationship between the total number of papers by an industry and the diversity of the industrial sector knowledge base ( $p$-value equal to0.78). There are some sectors with a limited of scientific publications, yet they remain relatively broadly spread across a range of fields, such as non-electrical 
Table 1: Spread of industrial scientific publications across scientific disciplines by industrial sector

\begin{tabular}{lccrr}
\hline \hline & $\begin{array}{c}\text { Number of } \\
\text { Scientific Fields } \\
(\mathrm{c}=77)\end{array}$ & $\begin{array}{c}\text { Herfindahl } \\
\text { Index }\end{array}$ & $\begin{array}{c}\text { Number of } \\
\text { publications }\end{array}$ & $\begin{array}{c}\text { Number } \\
\text { of Firms }\end{array}$ \\
\hline Petroleum refineries & 57 & 0.065 & 2424 & 11 \\
Industrial chemicals & 75 & 0.086 & 6395 & 20 \\
Non-electrical machinery & 30 & 0.096 & 134 & 4 \\
Other transport equipment & 36 & 0.109 & 239 & 7 \\
Fabricated metal products & 25 & 0.110 & 111 & 3 \\
Rubber and plastics & 38 & 0.112 & 251 & 5 \\
Food, drink and tobacco & 52 & 0.116 & 880 & 9 \\
Aerospace & 44 & 0.117 & 462 & 9 \\
Pharmaceuticals & 73 & 0.119 & 12478 & 46 \\
Office machines and computers & 39 & 0.132 & 315 & 9 \\
Motor vehicles & 19 & 0.150 & 41 & 2 \\
Instruments & 45 & 0.187 & 394 & 6 \\
Stone, clay and glass & 65 & 0.199 & 3629 & 20 \\
Iron and Steel & 20 & 0.249 & 165 & 1 \\
Non-ferrous metals & 21 & 0.254 & 118 & 2 \\
Communication eq. and semiconductors & 35 & 0.315 & 2354 & 6 \\
Electrical machinery & 40 & 0.405 & 2559 & 12 \\
\hline \hline
\end{tabular}

Note: The Herfindahl Index is calculated as $\sum_{i=1}^{c}\left(n_{i} / N\right)^{2}$, where $c$ is the number of scientific fields, $n_{i}$ the number of papers in field $i$ and $N$ is the total number of papers in all fields.

machinery. ${ }^{1}$ This suggests that even in sectors where the relationship between scientific research and industrial practice appears to be weak, as represented here by the number of publications, there is still a need to access research from a wide range of fields.

These findings stress in the importance of a broad science base for supporting industrial innovation. They confirm the earlier findings by one of us (Laursen, 1996). In this study of the pharmaceutical sector among OECD countries, scientific strength across all scientific fields appeared to have a greater impact on shaping patterns of specialisation in the pharmaceutical industry than could be accounted for by specialisation purely in life science fields of science, indicating the importance of the breath of the science-base in shaping patterns of economic specialisation.

These data represents a challenge to science policy initiatives that attempt to support industrial innovation in a particular sector by investing a narrow range of

1 The techniques used in this paper do not consider the role of the research as the boundaries of existing disciplines. Often research at the interstices of existing disciplines is responsible for the significant economic impact. Because our data set is arranged by the ISI disciplines, we are not able 
scientific disciplines. The data shows that diversity is an essential characteristic of industrial interaction with the science base. Industrial firms need, use and publish in a wide range of scientific fields. Research policies seeking to limit diversity and concentrate investments in a limited number of "strategic" fields of research, often with the explicit intent of supporting innovation in a particular sector, may find that these policies yield meagre results.

\subsection{The variables}

The dependent variable in our econometric analysis is Revealed Production Advantage (c.f. Balassa, 1965). The algebra can be set up as follows :

$$
R P A_{i j}=\left(Y_{i j} / \sum_{i} Y_{i j}\right) /\left(\sum_{j} Y_{i j} / \sum_{i} \sum_{j} Y_{i j}\right),
$$

where the numerator represents the percentage share of a given sector in national manufacturing $-Y_{i j}$ is production of sector $i$ from country $j$. The denominator represents the percentage share of a given sector in OECD17 manufacturing production. The RPS index thus contains a comparison of national production structure (the numerator) with the OECD17 production structure (the denominator). When $R P A$ equals 1 for a given sector in a given country, the percentage share of that sector is identical with the OECD17 average. Where RPA is above 1 the country in question is said to be specialised in that sector and vice versa where RPA is below 1 . However, since the $R C A$ turns out to produce an output which cannot be compared on both sides of 1 , the index is made symmetric, obtained as $(R P A-1) /(R C P+1)$; this measure ranges from -1 to +1 . The measure is labelled "Revealed Symmetric Production Advantage" (RSPA). ${ }^{2}$

In most empirical studies on the determinants of international manufacturing specialisation (typically measured as trade specialisation) and performance, cost and technology factors have been identified as the major factors (Soete, 1981; Amable and Verspagen, 1995; Gustavsson, Hansson and Lundberg, 1999; Laursen and Drejer, 1999). When conducting an analysis of the relationship between national scientific specialisation and strength on the one hand, and economic specialisation on the other hand, it is therefore necessary to control for these "standard" factors.

to explore research operating across the boundaries.

2 For discussion of this topic, see Laursen (2000). 
Cost competitiveness is generally measured by either wages per employee or unit labour costs. Here we use unit labour costs since the level of wages per se can be related to labour productivity and therefore its effects on export shares might be ambiguous. Our measure is defined as follows:

$$
U L C_{i j t}=\left(W_{i j t} / V A_{i j t}\right) /\left(\sum_{j}\left(\left(W_{i j t} / V A_{i j t}\right) / n\right)\right.
$$

where $W_{i j t}$ is the wage sum of country $j$, in sector $i$, at time $t$, expressed in current prices and $V A_{i j t}$ is value added in fixed prices; $n$ is the number of countries. ${ }^{3}$ Since the RHS variable (and the other LHS variables) is measured in relative terms we divide by the average value of the 17 countries for each given time and sector.

Different contributions have used different proxies in order to measure technological specialisation. The most commonly used measures of disembodied technology are R\&D and patent statistics: the former is better suited to capture the inputs to the innovation process while the latter is a measure of the innovation output. In this paper, we have chosen to work with US patent data, mainly because R\&D data is only available for a more limited sample of countries. The technological specialisation variable is therefore defined in a similar way to the RSPA from above, but in this case the input to Equation (1) is not production, but instead US patents by sector, country and time. In this case we obtain the "Revealed Symmetric Technological Advantage". In order to avoid problems of small numbers, it can be noted that the patents have been aggregated four years back, while using linear depreciation over time.

We include two measures of scientific activity relevant to our 17 industrial sectors: one variable measures the scientific strength (or performance), and another variable measures scientific specialisation. These two scientific variables are the key for our analysis. First, — and in order to adjust for the unequal size of scientific disciplines — the concordance table is weighted by the size-distribution across the 77 scientific disciplines (based on the cumulated publications from the ISI database for all the relevant years). In this way we obtain an adjusted concordance table. Second, the adjusted concordance matrix (77 fields of science $x 17$ industrial sectors) is

3 Note that our sample includes four-digit ISIC sectors for which no constant price value added are available (pharmaceuticals, computers and office machines, electronics, other transport, aerospace). For these sectors, we use the corresponding three-digit (implicit) price indices for calculating constant 
multiplied by the ISI publication data (also 77 fields of science) for each year (13 years; 1981-1993) and country (17 countries), field by field. As a result, we are able to assess how much the researchers of each country publish in each field, relevant to each of the 17 manufacturing sectors (labelled the "output-relevance" matrices). Both of the scientific variables, the measure of the scientific strength and the variable measuring scientific specialisation, are based on the result of these calculations.

The variable measuring scientific performance relevant to each of the 17 industrial sectors is obtained by calculating the share (the 17 countries add up to 100 per cent) possessed by a given country for each of the 77 scientific fields, on the basis of the "output-relevance" matrices. The variable is then subsequently obtained by adding up the 77 fields for each of the 17 industrial sectors, while adjusting for country size by dividing by the size of the population for each country. In this way we get a single figure measuring the "relevant" scientific strength for each industrial sector, country and year (labelled SP, i.e. short for "Scientific Performance").

The variable measuring specialisation relevant to each of the 17 industrial sectors is obtained by calculating a "comparative advantage figure" (analogues to Eq. 1) based on the "output-relevance" matrices. The specialisation figures for the 77 fields of science are then added up to a single figure for each industrial sector, country and year. However, since by following this procedure, we are likely to get countries "specialised" in all fields, we normalise the result by calculating yet another comparative advantage figure, across the 17 industries for each country and time. In this way we obtain the "Revealed Symmetric Scientific Advantage" (RSSA).

\section{Econometric analysis}

Based on the variables described above the model to be estimated, can be set up as follows:

$$
R S P A_{i j t}=\beta_{1 i}+\beta_{2 j}+\beta_{3 i} R S T A_{i j t}+\beta_{4 i} U L C_{i j t}+\beta_{5 i} S P_{i j t}+\beta_{6 i} R S S A_{i j t}+\varepsilon_{i j t}
$$

where $\beta_{1 i}$ is a sector-specific effect and $\beta_{2 j}$ is a country-specific effect, and $\varepsilon_{i j t}$ is the error term. Footsign $i$ on the parameters indicates that the model is to be estimated

price value added. 
while allowing the slopes to differ in the sectoral dimension. ${ }^{4}$

We expect all parameters to have a positive sign, except for the parameter for unit labour costs. In the case of for unit labour costs, the effect on economic specialisation can be ambiguous. From the point of view of production cost, we would expect high ULCs to lead to low specialisation in a given sector. However, as high wages might be associated with high skill levels, low wages might also lead to a low degree of specialisation (Amable and Verspagen, 1995: 200).

The results of the estimation of Equation 3 are displayed in Table 2. From the Table, it can be seen that technological specialisation (RSTA) is an important factor in explaining specialisation in terms of production, since the parameter for this variable is significant for thirteen out of seventeen industrial sectors. Hence, it can be concluded that technology plays a role for economic specialisation, not only in hightech industries, but also in medium- and in some low-tech industries. For unit labour costs, eight of the seventeen coefficients are negative, and five of these coefficients are significant (pharmaceuticals; stone, clay and glass; iron and steel; non-ferrous metals; other transport equipment). Six coefficients are positive and significant (food, beverage and tobacco; non-electrical machinery; electrical machinery; communication equipment and semiconductors; motor vehicles; instruments).

For what concerns the science variables, it can be seen from Table 1, that the coefficients for scientific strength are positive and significant in nine out of seventeen cases (industrial chemicals; pharmaceuticals; fabricated metal products; non-electrical machinery; office and computing machinery; other transport equipment; motor vehicles; aerospace; instruments). Moreover, the coefficients are positive and significant in the case of six industries (food, drink and tobacco; industrial chemicals; rubber and plastic products; stone, clay and glass; iron and steel; aerospace) for the scientific specialisation variable. Hence, these results show - in general and as expected - that most industries with strong science-based

\footnotetext{
4 It can be noted that we do not want to make inferences concerning Granger-causality between the science variables and economic specialisation. Given the relative short time-period for which we have data, such an analysis would provide little information, since the co-evolution between the economic and the science systems has happened over decades, and even in some cases over centuries.
} 
Table 2: Regression results explaining specialisation in manufacturing production over the period 1981-1993, across 17 OECD countries $(n=3377)$

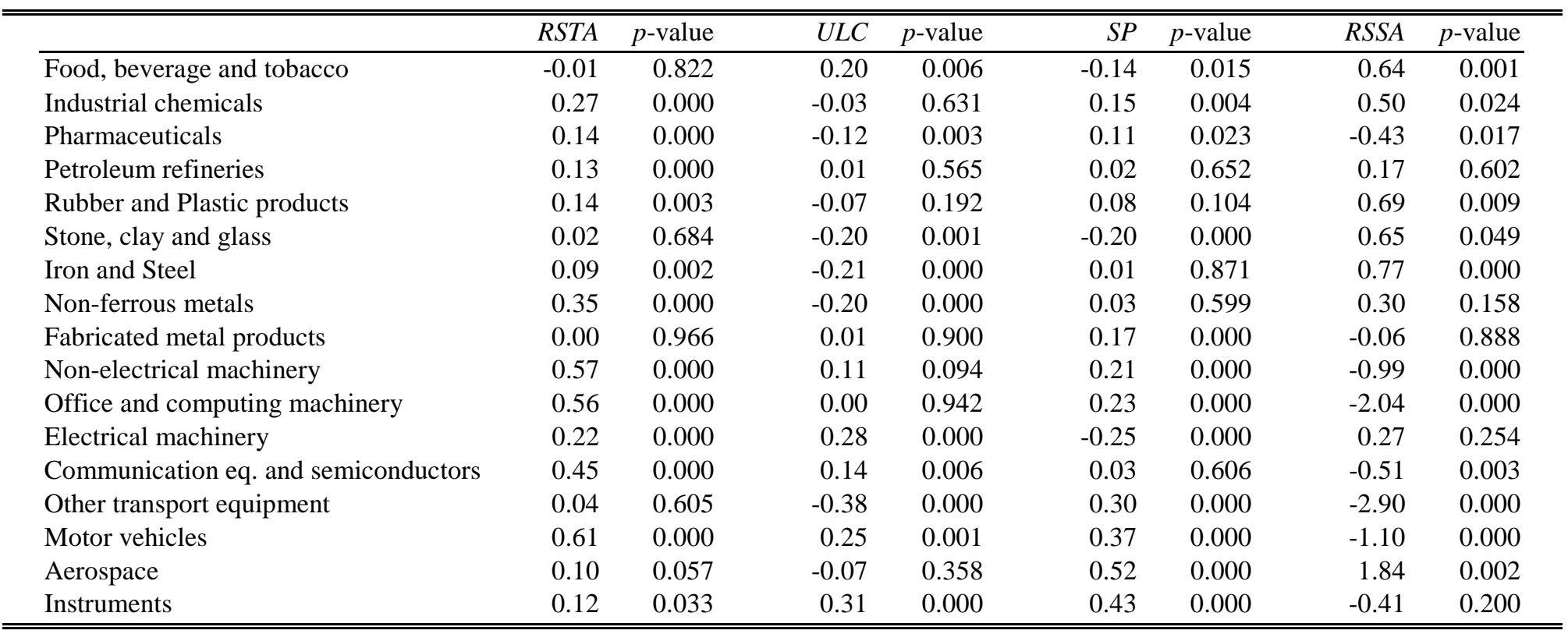

Note: Adj. $R^{2}=0.61$. Sector and country specific constants included, but not reported for reasons of space. 
properties $^{5}$ (industrial chemicals; pharmaceuticals; office and computing machinery; aerospace; instruments) rely on the availability of relevant scientific strength (scientific output at a world-class level) held by the given country. ${ }^{6}$ However, a number of scaleintensive sectors appear to need relevant scientific strength (fabricated metal products; other transport equipment; motor vehicles). The common denominators for the industries which rely on scientific specialisation (rather than on performance) appear to be that these industries are in general either natural resource based (food, drink and tobacco; stone, clay and glass; iron and steel) or scale intensive (industrial chemicals; rubber and plastic products). ${ }^{7}$

\section{Conclusions}

Using a variety of data sources, this paper has explored the relationship between scientific activity and economic specialisation. We have found a link between scientific activity and economic specialisation across a number of industrial sectors. This finding upholds Marx's view that intellectual production is strongly related to material production. Production specialisation is indeed related to scientific activity. The dialectical or co-evolution view of the relationship between science and production is largely correct. This finding further strengthens the view that the science system is responsive to industrial and social needs. Derek de Solla Price's metaphor of the relationship between science and technology as "dance partners" can be equally applied to science and production.

In particular, we found that for most science-based and for some scale-intensive sectors, there is indeed a statistically significant association between relevant scientific performance and economic specialisation. We take this as an indication of a rather direct link to the underlying science-base for what concerns these industries. In addition, we found a significant and positive relationship between relevant scientific specialisation

5 For a classification of the STAN sectors into the Pavitt taxonomy (supplier dominated, science-based, scale-intensive and specialised suppliers), see Laursen and Meliciani (2000).

6 In fact, all science-based industries, but communication equipment and semiconductors, appear to rely on relevant national scientific performance.

7 It can be noted that the two significant science-based industries, aerospace and industrial chemicals, both 
and economic specialisation for most natural resource based industries and for some scale-intensive industries. For these industries, we take the results as an indication of a much more indirect link to the scientific system, possibly mediated through the educational system.

Our analysis also showed that industries draw from a wide variety of scientific disciplines and the diversity of the science base can play an important role in explaining production specialisation. We have suggested that policies aiming to support particular industries by making investments in a narrow range of disciplines commonly associated with those sectors will yield only limited results. A broad approach, supporting research across a number of disciplines, may generate more industrial activity.

There are many limits to our approach given both the problems with the available datasets and to our macro-approach to studying the links between scientific and production specialisation. The industrial publications are for one country, the scientific specialisation data runs from only 1981 to 1993 and the production specialisation indicator is a partial reflection of the production sphere. Further refinement of the method is required.

The paper points to new areas for research. One area for further development is crosscountry comparisons. Our current approach uses country dummies to discount the role of country-specific features. It would be useful in the future to explore the patterns of specialisation within and between countries. In particular, it would useful assess the fitness between individual country's science system and its patterns of production specialisation. A second line inquiry could involve exploring changes over time in patterns of specialisation to see if science systems are becoming more or less closer in structure to the patterns of production specialisation. The current data makes these time series estimates extremely difficult. A longer time series and more advanced econometrics might make this analysis possible. If possible, this approach would show whether science leads production specialisation or vice-versa. A third approach would be to explore role of different fields of science in explaining production specialisation. It might be possible to find a number of leading fields of science that have capacity to alter patterns of specialisation across countries.

have science-based as well as scale intensive properties (see Laursen and Meliciani, 2000: 708). 


\section{References}

Amable, B. and B. Verspagen, 1995, The role of technology in market shares dynamics, Applied Economics 27, 197-204.

Arundel, A. and A. Geuna 2000, 'Does Localisation Matter for Knowledge Transfer among Public Institutes, Universities and Firms?', paper presented at the 8th Joseph Schumpeter Conference: Change, Development and Transformation, University of Manchester, 28 June - 1 July.

Arundel, A., G. van de Paal and L.L.G. Soete, 1995, Innovation Strategies of Europe's Largest Industrial Firms, PACE Report (MERIT, University of Limburg, Maastricht).

Balassa, B., 1965, Trade Liberalization and 'Revealed' Comparative Advantage, The Manchester School of Economic and Social Studies 32, 99-123.

Bernal, J.D., 1939, The Social Foundation of Science (Routledge and Kegan Paul, London).

Brusoni, S. and A. Geuna, 2001, Persistence and Integration: The Knowledge Base of the Pharmaceutical industry, in: C. C. Antonelli, D. Foray, G.M.P. Swann and W.E. Steinmueller (Editors), Technical Choice, Innovation and Knowledge: Essays in Honour of Paul A. David (Edward Elgar, Cheltenham).

Bush, V., 1945, Science and the Endless Frontier (National Science Foundation, Washington D.C.).

Christensen, C., 1997, The Innovator's Dilemma: When New Technologies Cause Great Firms to Fail (Harvard Business School Press, Cambridge, Massachusetts).

Etzkowitz, H., A. Webster, C. Gebhardt and B. Terra, 2000, The future of the university and the university of the future: evolution of ivory tower to entrepreneurial paradigm, Research Policy 29, 313-330.

Freeman, C. and L.L.G. Soete, 1997, The Economics of Industrial Innovation (Pinter, London).

Gibbons, M., C. Limoges, H. Nowotony, S. Schwartzman, P. Scott and M. Trow, 1994, The New Production of Knowledge (Sage, London).

Godin, B., 1996, Research and the practice of publication in industries, Research Policy 25, 587-606.

Gustavsson, P., P. Hansson and L. Lundberg, 1999, Technology, resource endowments and international competitiveness, European Economic Review 43, 1501-1530.

Hicks, D., 1995, Published papers, tacit competencies and corporate management of the public/private character of knowledge, Industrial and Corporate Change 4, 401-424.

Hicks, D., T. Breitzman, D. Olivastro and K. Hamilton, 2001, The changing composition of innovative activity in the US --- a portrait based on patent analysis, Research Policy 30, 681-703.

Hicks, D. and J.S. Katz, 1997, The British Industrial Research System, SPRU Working Paper (University of Sussex, Brighton).

Klevorick, A.K., R.C. Levin, R.R. Nelson and S.G. Winter, 1995, On the sources and significance of interindustry differences in technological opportunities, Research Policy 24, 185-205.

Laursen, K., 1996, Horizontal Diversification in Danish National System of Innovation: the Case of Pharmaceuticals, Research Policy 25, 1121-1137.

Laursen, K., 2000, Trade Specialisation, Technology and Growth: Theory and Evidence From Advanced Countries (Edward Elgar, Cheltenham, UK and Lyme, US). 
Laursen, K. and I. Drejer, 1999, Do Inter-sectoral Linkages Matter for International Export Specialisation?, The Economics of Innovation and New Technology 8, 311330.

Laursen, K. and V. Meliciani, 2000, The Importance of Technology-Based Intersectoral Linkages for Market Share Dynamics, Weltwirtschaftliches Archiv 136, 702-723.

Martin, B. and R. Johnston, 1999, Technology foresight for wiring up the national innovation system - Experiences in Britain, Australia, and New Zealand, Technological Forecasting and Social Change 60, 37-54.

Mowery, D. and N. Rosenberg, 1979, The influence of market demand upon innovation: A critical review of some recent empirical studies, Research Policy 8, 102-153.

Mowery, D.C., R.R. Nelson, B.N. Sampat and A.A. Ziedonis, 2001, The growth of patenting and licensing by U.S. universities: an assessment of the effects of the BayhDole act of 1980, Research Policy 30, 99-119.

Narin, F., Hamilton, K.S. and Olivastro, D., 1997, The increasing linkage between us technology and public science, Research Policy 26, 317-330.

Narin, F. and D. Olivastro, 1992, Status report: linkage between technology and science, Research Policy 21, 237-249.

Nelson, R.R., 1994, Economic Growth via the Coevolution of Technology and Institutions, in: L. Leydesdorff and P.v.d. Besselaar (Editors), Evolutionary Economics and Chaos Theory: New Directions in Technology Studies (Pinter, London).

Nelson, R.R. and N. Rosenberg, 1994, American universities and technical advance, Research Policy 23, 323-348.

Pavitt, K.L.R., 2000, Public policies to support basic research: What can the rest of the world learn from US theory and practice? (And what they should not learn), SPRU Electronic Working Papers Series no. 53 (SPRU, University of Sussex, Brighton).

Polanyi, M., 1962, The republic of science: Its political and economic theory, Minerva 1, 54-73.

Rosenberg, N., 1976, Perspectives on Technology (Cambridge University Press, Cambridge).

Salter, A. and B.R. Martin, 2001, The economic benefits of publicly funded basic research: a critical review, Research Policy 30, 509-532.

Schmookler, J., 1966, Invention and Economic Growth (Harvard University Press, Cambridge, Massachusetts and London).

Soete, L.L.G., 1981, A general Test of the Technological Gap Trade Theory, Weltwirtschaftliches Archiv 117, 638-666. 